\title{
Rasgos de la permanencia de los partidos políticos uruguayos
}

Gonzalo Varela

UAM-XOCHIMILCO

\begin{abstract}
En este ensayo se revisan las causas que han determinado, en el largo plazo, la permanencia del sistema de partidos políticos en Uruguay. Se advierte, contra una explicación tautológica de esta característica, que sólo se repite en muy pocos países de América Latina. La centralidad del sistema de partidos debe ser entendida no como rasgo intrínseco, sino como capacidad de respuesta y de cambio ante los eventos históricos del país.
\end{abstract}

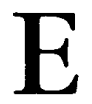

I tema que enuncia el título de este trabajo es vasto y variado, sobre todo si tomamos en cuenta que alude a un periodo largo. Por tanto, haremos sólo un abordaje selectivo de puntos que nos parecen centrales.

En primer lugar, es claro que lo interesante del caso uruguayo radica muy particularmente en la permanencia de los dos partidos llamados "tradicionales" (Partido Colorado y Partido Nacional), que han ocupado un lugar predominante en la escena política desde el siglo XIX hasta nues- tros días. ${ }^{1}$ Con excepción de Colombia, Costa Rica u Honduras no sucede lo mismo en otros países latinoamericanos (o inclusive europeos) que en el cambio de un siglo a otro o en el correr del siglo $\mathrm{xx}$, vivieron un reciclamiento completo de su sistema de partidos.

En segundo lugar está la comprobación de lo que Gerardo Caetano y otros especialistas llaman "centralidad partidaria"; es decir, que los partidos no sólo persisten, sino que son

1 Pivel Devoto, Historia, 1942. 
el eje del sistema político, y esto último es extensible a los partidos no tradicionales, fundamentalmente los de izquierda. ${ }^{2}$

Sin embargo, no debemos caer en la tentación de fetichizar a los partidos o al sistema de partidos uruguayo. No digo que éste sea el caso de Gerardo Caetano -cuyos trabajos históricos contienen más que suficientes elementos de problematización-, pero a veces puede surgir la tentación de pensar que los partidos son así porque son uruguayos, que son fruto de una especie de idiosincrasia nacional irreductible e intemporal. Por el contrario, debemos ver a la historia como cambio constante $y$, al verificar continuidades, debemos suponer que las mismas se dan también, paradójicamente, con base en el cambio. Es decir, que hay símbolos y formas de organización que permanecen porque han sido capaces de transformarse.

$\mathrm{Y}$ esto sugiere que, pese a las apariencias, hay cierta fragilidad potencial en la permanencia de los partidos de cara a la historia. Dicho fenómeno no es directamente visible en Uruguay considerado aisladamente, pero sale a luz en una comparación con países vecinos como Argentina, con los que comparte mucha historia, o incluso con otros más lejanos como México. Todo el debate del siglo XIX -o más que el debate, la guerra- entre unitarios y federales, así como las luchas entre liberales y conservadores guardan en todos estos casos bastante paralelismo; pero en determinado punto

\footnotetext{
2 Cactano, Sistema, 1985, y Cactano, Rilla y Pérez, Partidocracia, 1987.
}

del transcurso histórico de Argentina o de México (o de otros países latinoamericanos), esta dinámica se interrumpe para dar paso a una anulación de los viejos partidos.

Apelamos a tal comparación no para negar la especificidad uruguaya, sino para sugerir que la misma, puesta a contraluz de la historia, nos deja la sensación de que hubo varios derroteros posibles a partir de puntos de partida similares, y que por tanto hay también puntos frágiles en la estabilidad o permanencia de los partidos uruguayos que algún día podría cambiar.

Pero ciñámonos más estrechamente a la historia de los partidos políticos uruguayos para poder referirla a algo que está muy vinculado a ellos: que es el surgimiento, el desarrollo y la integración de un sistema político nacional paralelo al desarrollo partidario. Es algo muy vinculado pero peculiar y distinto: se trata de la estructuración progresiva de un sistema político como algo más amplio que los partidos, y a lo que se integran éstos.

En el periodo inmediatamente posterior a la independencia, el Uruguay vivió primero esa fase de guerras civiles que fue muy común en muchos países de América Latina, pero con una característica central: que ningún enemigo pudo eliminar al otro (a diferencia por ejemplo, de México, donde luego de la derrota de la intervención, el triunfo del liberalismo se volvió aplastante, preparando paradójicamente el camino a la dictadura de Porfirio Díaz). En esta primera instancia no hubo en Uruguay un sistema político propiamente dicho, sobre to- 
do en los momentos de confrontación bélica. Porque para hablar de un sistema político a nivel nacional, un requisito crucial es que no haya una excesiva fragmentación política, como la que produce una situación de inestabilidad aguda y guerra civil reiterada.

Es cierto que existieron, desde el inicio de la historia política nacional, "doctores" relativamente más civilistas, civilizados y urbanos, que pensaban la organización nacional en los términos del derecho constitucional europeo, lo que sin duda encerraba la idea de construir un sistema político moderno. (Aunque no hay que olvidar que, muy a menudo, los doctores entraban también con gusto a la guerra civil.) Así como había también, en Uruguay y en otros países latinoamericanos, una idea de modernización económica y social, que nos revela la lectura de intelectuales y políticos entonces relevantes. Sin embargo, más allá de estos esbozos, es evidente que la guerra absorbía a la política en una medida que hacía difícil la concreción de un sistema, entendido como unidad capaz de contener a las partes en conflicto, moderando la lucha.

Luego adviene un segundo periodo, y en relación con el mismo quisiéramos plantear por lo menos una duda terminológica, puesto que lo que en la historia uruguaya se suele llamar coparticipación, en realidad se trata más bien de una distribución del poder, por cuanto, en nuestra opinión, la coparticipación en sentido estricto viene después, en el siglo XX, cuando los dos partidos tradicionales realmente cogobiernan al país. Antes, entre la Paz de Abril de 1872 y los comienzos del siglo $\mathrm{XX}$, se da lo que llamaríamos etapa de distribución del poder nacional, en el sentido de que no hay un cogobierno estricto del conjunto del país por ambos partidos, sino que éstos se ponen de acuerdo para gobernar cada uno, en forma excluyente, una parte del territorio. Por supuesto se mantenían ciertas funciones unificadas de gobierno nacional, como las relaciones exteriores, $y$ esto quedaba en manos del gobierno central formalmente detentado por el Partido Colorado, pero fuera de esto no había una integración real de todo el territorio nacional y sus habitantes en un único sistema jurídico y político.

Teóricamente ello estaba previsto en la Constitución, pero en la práctica se daba una distribución segmentada del poder con base en un reparto geográfico. Hay que subrayar lo territorial, puesto que la base de constitución de un Estado moderno radica, para empezar, en la fijación de un territorio. La distribución interpartidaria apuntaba a tal meta por cuanto, más allá de las divisiones, se mantuvo finalmente la delimitación y la preservación del territorio en manos de ambos partidos. Pero antes del siglo $\mathrm{xx}$ ello distaba de coincidir con la estructuración de un verdadero sistema político nacional.

Esto último se da en una tercera etapa, aproximadamente desde la primera y segunda década del siglo $\mathrm{xx}$, consagrándose la coparticipación entendida como un cogobierno virtual de los dos partidos mayoritarios en todo el país, que cobra una gran fuerza y se extiende hasta la crisis de los años setenta. Dicha fase está marcada 


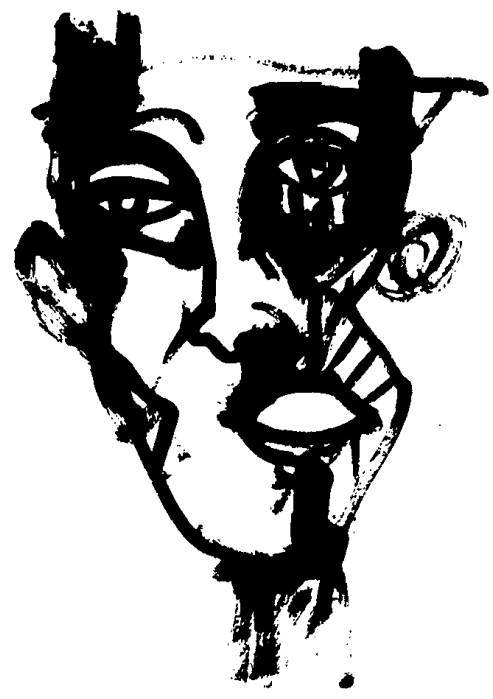

por la interpenetración de los dos partidos tradicionales en el poder y por la maduración de un mecanismo que ya venía del siglo XIX, el de los pactos inter e intrapartidarios para poder construir acuerdos básicos de gobierno. (Lo interesante de la historia más reciente es que parece que ahora ese cogobierno partidario se va a hacer de tres, después de que la ciudad de Montevideo, que concentra a la mitad de la población del país, ha caído bajo el control político de los partidos de izquierda.)

Éste es, en suma, el itinerario de construcción de un sistema político moderno, partiendo de la guerra civil, pasando por la distribución territorial del poder que consagra una primera estabilización de la política, y finali- zando con la coparticipación. Y así madura una serie de reglas de juego que garantizan la competencia electoral y se verifica una ley que dice que, habiendo elecciones limpias, nadie puede resisitir indefinidamente a la competencia electoral. Por eso en 1958 se produce una gran derrota electoral del Partido Colorado, que había predominado en el gobierno nacional desde 1865, así como desde 1971 la izquierda también se proyecta como un fuerte rival electoral de los partidos tradicionales.

Pero esta misma ley de declinación relativa de los grandes partidos puede y debe explicarse en referencia a su actuación en el seno de un sistema político que implica transferencias periódicas de votos de unas fuerzas a 
otras. Porque tales cambios son también formas de sanear al sistema, para que las tensiones o frustraciones producidas por los fracasos administrativos y políticos de los partidos en el poder no redunden en una destrucción global del sistema.

Otro tema no menos importante es el de los actores no partidarios del sistema político. Los partidos son siempre importantes, aunque no tanto como en Uruguay. En este sentido hay variaciones por país, porque en términos generales un sistema político no comprende sólo a partidos, sino a todo tipo de actores capaces de constituirse como tales y de insertarse $y$ jugar en las redes de poder del sistema. Y en concreto, a partir de la industrialización, se registra un peso político creciente de las agrupaciones laborales y profesionales, generando ese fenómeno político sui generis que se ha dado en llamar corporativismo y que en América Latina en el siglo $\mathrm{XX}$ se vincula especialmente al populismo (aunque no en el caso de Uruguay, como veremos más adelante).

Incluso en un país como Uruguay, en que no adquirió las dimensiones que tuvo en México, Brasil o Argentina, la industrialización logró de todos modos un impacto muy considerable en la sociedad. ${ }^{3}$ Con ella surgen nuevos actores, fundamentalmente los sindicatos, que en la historia uruguaya han pesado mucho y nos dan la verdadera dimensión de la influencia política de la izquierda. Cuando la izquierda no era aún una fuerza electoral rele-

${ }^{3}$ Lamas y Piotti, Historia, 1981, y Rodriguez, Nuestros, 1965. vante, tenía sin embargo un peso muy significativo por su participación en los sindicatos. Y en relación con ello hay algo muy interesante, que sólo podemos mencionar de pasada, y es que si observamos las cifras electorales y las cifras de afiliación y acción sindicales, llegamos a la conclusión de que en Uruguay, por lo menos hasta los años sesenta, muchos trabajadores votaban a los partidos tradicionales para el gobierno, pero a su vez apoyaban a sus sindicatos en las empresas, a sindicatos que eran claramente de izquierda.

Este contrasentido aparente tiene mucha lógica desde el punto de vista de personas que eran a la vez electores y sindicalizados: por un lado votaban al sistema político que les había dado trabajo (puesto que el Estado, por vía directa o indirecta, regía la política de empleos) y por otro apoyaban al sindicato que mejoraba y defendía sus condiciones laborales. Pero en el contexto del sistema político, este fenómeno lo tenemos que ver también como una penetración del sistema por organizaciones no partidarias, que van adquiriendo una fuerza casi tan grande como la de los partidos tradicionales. Por otra parte, la historia también nos muestra que el "doble juego" de los votantes en ciertas coyunturas cambia, y la izquierda empieza a crecer también en cantidad de votos.

Otro punto a analizar es el de la fobia antipartidaria que se desarrolló en Uruguay a la sombra de la crisis económica y política que se inició a fines de los años cincuenta. Este es el lado de sombra de la centralidad partidaria: hasta 1971 los electores siguie- 
ron votando masivamente a los dos partidos tradicionales, pero éstos ya no estaban en condiciones de garantizar, como en el pasado, condiciones de bienestar social y económico a sus votantes, lo que da lugar a un descontento creciente con los partidos $\mathrm{Na}$ cional y Colorado, una crítica que encarna incluso en la derecha con el fenómeno del "ruralismo". 4 Pero son por supuesto la izquierda y los sindicatos quienes más canalizaron el descontento. $Y$ en esta circunstancia se desarrolla no sólo una fuerte crítica contra los partidos tradicionales, sino una posición antipartido en general, que rebasó a la izquierda convencional y encarnó en la organización clandestina de los Tupamaros -que ni siquiera quiso llamarse "partido", sino que eligió la palabra "movimiento"-y que implicó entre otras cosas un intento de demolición de la cultura política tradicional uruguaya, con bastante éxito en algunos momentos.

El desarrollo de esta fobia contra los partidos tiene mucho que ver, en nuestra opinión, con la crisis económica y la subsecuente falla del clientelismo partidario como distribuidor de bienes de distinto tipo a la población. Los últimos -pero no los menoresfóbicos antipartidarios fueron los militares, que echaron la culpa del desastre nacional a los partidos tradicionales tanto como a la subversión. 5

Ahora bien, dada la extensión de esta crítica antipartidos, ¿cómo fue posible la recuperación actual de los

\footnotetext{
4 Raúl Jacob, Benilo, 1981.

5 Sobrc esta crisis, Gonzalo Varch, República, 1988.
}

partidos? Es especialmente aquí donde debemos rechazar una explicación tautológica de la centralidad partidaria por la centralidad partidaria. Debemos buscar un factor histórico nuevo (para la década de los setenta y ochenta) que nos explique la permanencia de lo tradicional y en verdad que, teniendo en mente a la dictadura militar de esos años, no es nada difícil hallar la explicación. Ésta radica en la brutalidad represiva de la dictadura en un país antes acostumbrado a un elevadísimo estándar de libertad política; en su nula o limitada capacidad (según los periodos) de elevar los deprimidos patrones de bienestar social, y también ¿por qué no? en el escaso margen de maniobra política que los militares se concedierón a sí mismos.

Pero hay algo no menos importante que señalara Guillermo O'Donnell hace algunos años. En algunos países como Chile y Uruguay, el "purgatorio" tan completo por el que pasaron los partidos políticos y las elites políticas profesionales durante las dictaduras militares los impulsó a revitalizarse. (En Uruguay podríamos sostener que, al menos en el caso del Partido Nacional, esta renovación ya se había iniciado un poco antes de la dictadura, pero de todos modos el argumento es válido para el conjunto del sistema de partidos.)

Y habiendo renovación también sigue existiendo y jugando, como nos muestran los trabajos de Silvia Dutrénit, ${ }^{6}$ lo tradicional, esa capacidad de los partidos y, especialmente de la

\footnotetext{
${ }^{6}$ Silvia Dutrénit, "Partidos", 1994, y Mare-
} moto, 1994. 
clase política que compone su dirigencia, de reanudar las prácticas de negociación y acuerdo que condujeron en 1984 al Pacto del Club Naval que, con todos sus bemoles, inicia la transición hacia la restauración democrática.

Habría otros puntos a comentar en este panorama, pero las dimensiones de este trabajo sólo nos permiten enunciarlos. Por ejemplo, la ausencia en Uruguay del populismo, tal como se dio en Argentina, Brasil o México. Pensamos que la respuesta está -ahora sí- en la centralidad de los partidos y sus clientelas, asociada al surgimiento temprano de un Estado de bienestar avanzado para su época. Lo que quita dos elementos que fueron significativos en los populismos mencionados: debilidad o virtual inexistencia de un sistema de partidos, unida a rezagos económicos y sociales.

Otra cosa es el enigma de por qué los militares uruguayos nunca se atrevieron a abolir los partidos existentes y a animar un "Partido del Proceso". Aparte de factores afectivos que no hay que descartar (muchos oficiales tenían un pasado político nacionalista o colorado) posiblemente una razón más profunda fuera que la permanencia (si bien meramente nominal, entre 1973 y 1980 ) de los partidos tradicionales constituyera un recurso para evitar un debate sobre nuevas formas de institucionalidad política que hu- bieran amenazado desgarrar al cuerpo de oficiales.

\section{BiBLIOGRAFIA}

-Caetano, Gerardo, "El sistema de partidos: raíces y permanencias", en Varios, De la tradición a la crisis, CLABH-EBO, Montevideo, 1985.

- José Rilla y Romeo Pérez, La partidocracia uruguaya, Cuadernos del CIAI:H, núm. 44, 1987.

-Dutrénit Bielous, Silvia, "Los partidos políticos uruguayos durante la dictadura. (Un enfoque histórico de sus actuaciones entre 1973-1981)", tesis de doctorado, UNAM, 1994.

, El maremolo militar y el ar chipiélago partidario. Testimonios para la historia reciente de los partidos políttcos uruguayos, Instituto Mora/Ediciones de Ciencias Sociales, Montevideo, 1994.

-Jacob, Raúl, Benito Nardone. II Kuralismo hacia el poder (1945-1958), Banda Oriental, Montevideo, 1981.

-Lamas, Mario Daniel y Diosma li. Piotti de Lamas, IIistoria de la industria en el Unuguay, 1730-1980, Cámara de Industrias del Uruguay, Montevideo, 1981.

-Pivel Devoto, Juan, Historia de los partidos políticos en el Uruguay, Medini, Montevideo, 1942.

-Rodriguez, Héctor, Nuestros sindicatos 1865-1965, Ediciones Uruguay, Montevideo, 1965.

- Varela, Gonzalo, De la república liberal al Estado militar. Crisis política en Uruguay 1968-1973, Nucvo Mundo, Uruguay, 1988. 


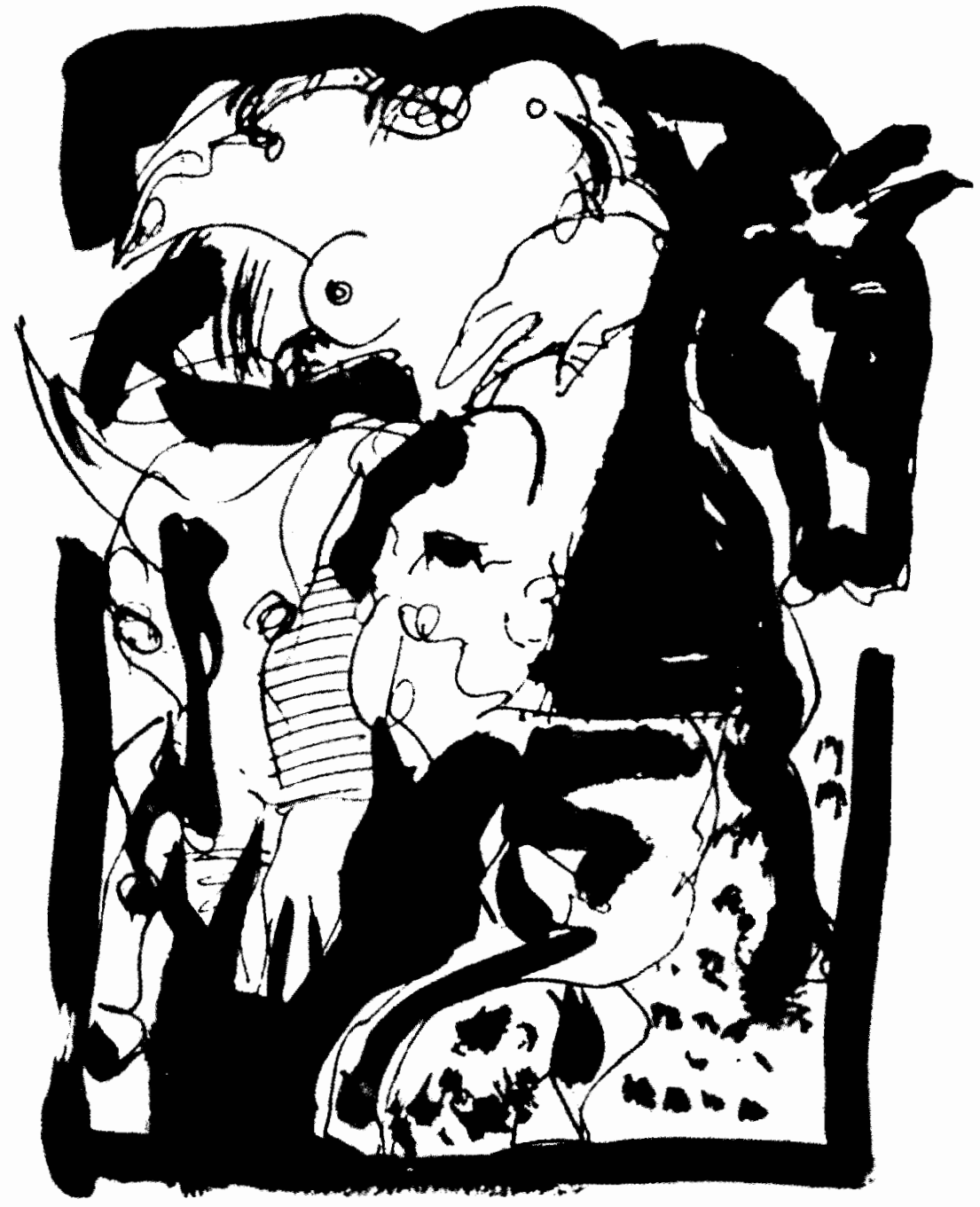

